\title{
Evaluation of plasma levels of tissue factor and tissue factor pathway inhibitor in patients with psoriasis
}

\author{
Anna Domagałaํㅡㄹ Elżbieta Wojtowicz-Prus ${ }^{1}$, Joanna Dubis ${ }^{1}$, Wojciech Witkiewicz ${ }^{1}$, Anna Czarnecka ${ }^{1,2}$ \\ ${ }^{1}$ Research and Development Centre, Regional Specialist Hospital, Wroclaw, Poland \\ ${ }^{2}$ Department of Cosmetology, Faculty of Physiotherapy, University of Physical Education, Wroclaw, Poland \\ Adv Dermatol Allergol 2019; XXXVI (4): 442-448 \\ DOI: https://doi.org/10.5114/ada.2019.87447
}

\begin{abstract}
Introduction: Psoriasis is a chronic, recurrent, inflammatory skin disorder with systemic involvement. It has recently been established that psoriasis is associated with an increased cardiovascular risk. Chronic skin-specific inflammation may promote atherosclerosis. Myocardial infarction or stroke can also be a result of underlying haemostasis disorders. Disorders in fibrinolysis and thrombosis in patients with psoriasis have been observed by many authors. Aim: This study points to the key role played by the tissue factor (TF) and tissue factor pathway inhibitor (TFPI) in the extrinsic pathway of blood coagulation and the potential influence of microvascular disorders in inflamed psoriatic skin on TF and TFPI activity.

Material and methods: The study included 47 patients with active psoriasis vulgaris, hospitalized in the Dermatological Ward of the Regional Specialist Hospital, Research and Development Centre in Wroclaw, as well as 18 people from the control group.

Results: There were significant differences in the blood concentrations of TF and TFPI in patients with psoriasis when compared to the control group. A low TFPI concentration in psoriatic patients may indicate an increased risk of atherosclerosis. Interpretation of a decreased level of TF in patients with psoriasis is difficult because it seems to be at odds with observations among patients with other atherosclerosis risk factors such as hypertension, hyperlipidaemia, diabetes or smoking.

Conclusions: It appears that further studies are necessary to explain this problem, perhaps to include an evaluation of TF levels in psoriatic skin.
\end{abstract}

Key words: psoriasis vulgaris, haemostasis, coagulation, cardiovascular diseases.

\section{Introduction}

Psoriasis is a chronic, recurrent skin disorder, affecting about $2-3 \%$ of the world's population, including the Polish population [1, 2]. It has been established that psoriasis is a systemic inflammatory disease [3], with the possibility of an underlying genetically determined disorder of the immunological mechanisms [4]. At the same time, there is an increased risk of cardiovascular diseases in patients with psoriasis [5, 6]. The chronic inflammation with an underlying immunological factor typical of psoriasis may be the cause of accelerated development of atherosclerotic lesions. The complications of a generalized atherosclerotic process, such as myocardial infarction or stroke, are also associated with the presence of certain haemostatic abnormalities.

\section{Haemostatic disorders in psoriasis}

The research carried out so far on the process of haemostasis in psoriasis has revealed some abnormalities in both the coagulation system and fibrinolysis [7-10], which may pose a risk of arterial and venous occlusive diseases in these patients. In determining plasma homocysteine levels in patients with psoriasis, Vanizor et al. [9] showed that the level of fibrinogen, fibronectin and plasminogen activator inhibitor (PAI) was elevated in these patients, while at the same time tissue PAI was lowered. Marongiu et al. [7] observed in their studies an increase in the concentration of by-products of thrombin and plasmin activity, i.e. fibrinopeptides $A$ and $B$ in patients suffering from psoriasis. In one of the first studies on the process of haemostasis in psoriasis, when assessing patients' platelets, Berrettini et al. [8] found their increased

Address for correspondence: Anna Domagała MD, PhD, Research and Development Centre, Regional Specialist Hospital, 73a Kamieńskiego St, 51-124 Wrocław, Poland, phone: +48 607990 123, e-mail: aniad05@gmail.com Received: 18.04.2018, accepted: 25.05.2018. 
capacity to activate and aggregate. Other researchers [10] demonstrated the presence of disorders in the metabolism of arachidonic acid and the activity of cyclooxygenase in the platelets of patients with psoriasis. TamagawaMineoka et al. [11] described increased concentrations of the so-called platelet-derived microparticles (PDMP) and P-selectins in the plasma of patients with psoriasis, as well as the relation of these concentrations and the severity of psoriasis. Elevated concentrations of PDMP and P-selectin correlated with the severity of psoriasis expressed by the Psoriasis Area and Severity Index (PASI). Płatek-Twardoch observed a decrease in the plasminogen concentration and decreased $\alpha 2$-antiplasmin activity in patients with psoriasis [12]. Iwan-Ziętek et al. showed that in psoriasis there is an activation of fibrinolysis, which is associated with elevated levels of tissue plasminogen activator (t-PA) produced in the vascular endothelium and in affected keratinocytes [13].

\section{Tissue factor and its inhibitor}

The contemporary concepts on activation and control of blood coagulation, associate tissue factor (TF) with a very important role, which initiates the so-called extrinsic coagulation pathway as co-factor VII [14]. Under normal conditions, plasma TF concentrations are virtually impossible to determine as they are found in the subendothelial tissue, in places physically separated from the circulating blood [14]. It is not until the endothelial cells are damaged by injury or proinflammatory cytokines that the TF comes directly into contact with circulating blood [15]. In the pathologically changed skin in the course of psoriasis, various microvascular disorders take place (extension of the capillary loops that fill the elongated dermal papillae, or defects in the vessel walls - the so-called 'gaps') [16], which may possibly facilitate the TF's contact with blood. Activated macrophages, keratinocytes and fibroblasts produce a number of proinflammatory cytokines, such as TNF, IL-1, IL-6, IL-8, which may also contribute to the initiation of the coagulation process by directly damaging the endothelium. The most important determinant inhibiting the procoagulant activity of the TF is its tissue factor pathway inhibitor (TFPI). This is a Kunitz-type protein produced by endothelial cells that have three domains that bind to: 1) activated TF/VII complex; 2) factor Xa; 3) plasma lipoproteins, mainly low-density lipoprotein (LDL), and to a lesser extent, high-density lipoprotein (HDL) [17]. Most of the TFPI found in the body is associated with endothelial cells. Circulating TFPI (referred to as total TFPI) is mostly (about 90\%) bound to plasma lipoproteins, while the remaining part (about 5\%) forms the so-called free TFPI and is present in blood platelets (5\%) [17]. TFPI has the ability to inhibit coagulation by inactivating TF/VIIA complex in two ways: 1) indirectly - by binding with active factor $X$; or 2) directly - by binding with TF/VIIA complex (when active factor $X$ is lacking). For direct TF/VIIA inactivation, however, a TFPI concentration about 50 times higher than in the case of indirect inactivation is necessary [18].

TFPI as a factor directly affecting haemostasis, exhibiting at the same time close associations with plasma lipoproteins, may play an important role in the pathogenesis of atherosclerosis. Perhaps this is the link connecting the two theories: coagulatory and lipid in terms of the formation of atherosclerotic plaques and in the process leading to the narrowing of the vessel and impaired blood flow. The reduced TFPI level is also considered a risk factor for deep vein thrombosis [19].

\section{Aim}

Due to the increased cardiovascular risk associated with psoriasis, it seems extremely important to extend the current knowledge on the role of haemostasis in this process. The aim of this study was to evaluate the concentration of TF and TFPI, which play a key role in the regulation of the extrinsic pathway of blood coagulation, in patients with psoriasis.

\section{Material and methods}

The study included 47 patients with active psoriasis vulgaris, hospitalized in the Dermatological Ward of the Regional Specialist Hospital, Research and Development Centre in Wrocław from June 2015 to June 2016, as well as 18 people from the control group. All patients gave their written consent to participate in the study. The study was approved by the Bioethics Committee of the Regional Specialist Hospital in Wrocław. The study included respondents aged 18 years and over. The diagnosis of psoriasis was determined on the basis of a typical morphology and distribution of the skin lesions. Patients with pustular and erythrodermic psoriasis were not included in the study. After obtaining written consent from the patient, an interview and a thorough clinical examination of the severity of the underlying disease (PASI assessment, method of treatment: local or general, duration of the disease, positive familial history of psoriasis, and coexistence of psoriatic inflammatory arthritis) were conducted. Furthermore, an assessment of the prevalence of cardiovascular diseases and their risk factors (body mass index (BMI), blood pressure values, smoking, premature cardiovascular events in the family, lipidogram, fasting glucose levels) was also conducted. The control group consisted of 18 healthy respondents, matched accordingly in terms of sex and age, without family history of psoriasis and with no risk factors for cardiovascular diseases.

Blood was collected from the antecubital vein of patients and healthy control individuals into a tube with anticoagulant (9 volumes of blood per 1 volume of sodium citrate). To obtain platelet-poor plasma for testing, the blood was centrifuged at $2000 \mathrm{~g}$ for $20 \mathrm{~min}$. The prepared 
Table 1. General characteristics of the patients and the control group

\begin{tabular}{lccc}
\hline Parameter & Study group & Control group & $P$-value \\
\hline Number of people in the group, $n$ & 47 & 18 & - \\
\hline Age [years]: & & & 0.85 \\
\hline Mean \pm SD & $46.4 \pm 15.9$ & $48.5 \pm 11.6$ & 25 \\
\hline Minimum & 19 & 69 & 0.58 \\
\hline Maximum & 70 & & $12(66.7 \%)$ \\
\hline Sex: & & $6(33.3 \%)$ & \\
\hline Women & $26(55.3 \%)$ & & \\
\hline Men & $21(44.7 \%)$ & & \\
\hline
\end{tabular}

SD-standard deviation.

Table 2. Characteristics of patients in the study group based on medical history and clinical examination

\begin{tabular}{lc}
\hline Characteristics & Result \\
\hline Patients with coexisting psoriatic arthritis & $6(9.2 \%)$ \\
\hline Duration of psoriasis [years]: & \\
\hline Mean \pm SD & $17.9 \pm 13.4$ \\
\hline Minimum & 1 \\
\hline Maximum & 56 \\
\hline Positive familial history of psoriasis & $15(31.9 \%)$ \\
\hline $\begin{array}{l}\text { Patients treated locally and/or with UVB } \\
\text { phototherapy in the past }\end{array}$ & $40(85.15 \%)$ \\
\hline Patients treated systemically in the past \\
(without biological drugs) & $19(40.4 \%)$ \\
\hline $\begin{array}{l}\text { Patients treated in the past with biological } \\
\text { drugs }\end{array}$ & $6(12.8 \%)$ \\
\hline People smoking cigarettes & $13(27.7 \%)$ \\
\hline $\begin{array}{l}\text { Patients with coexisting cardiovascular } \\
\text { diseases (IHD, HT) }\end{array}$ & $16(34.0 \%)$ \\
\hline $\begin{array}{l}\text { People with a family history of cardiovascular } \\
\text { disease }\end{array}$ & $12(25.5 \%)$ \\
\hline People with diabetes & $10(21.3 \%)$ \\
\hline People with cancer & $4(8.5 \%)$ \\
\hline PASI: & $22.8 \pm 4.5$ \\
\hline \begin{tabular}{l} 
Mean \pm SD \\
\hline Minimum
\end{tabular} \\
\hline Maximum
\end{tabular}

SD - standard deviation, UVB - ultraviolet B, IHD - ischaemic heart disease, $H T$ - hypertension, BP-blood pressure. material was immediately frozen and stored at $-86^{\circ} \mathrm{C}$. TF and TFPI plasma concentrations were measured using commercial immunoassay kits following the manufacturer's instructions. Plasma levels of TF were assayed using Human (TF) ELISA Kit while TFPI plasma levels were measured using Human TFPI ELISA Kit (Shanghai Sunred Biological Technology Co., Ltd). Routine biochemical tests, such as glucose, LDL and HDL were performed using standard laboratory methods.

There were no statistically significant differences in relation to age and gender between the study and control groups (Tables 1, 2).

\section{Statistical analysis}

Statistical analysis included the calculation of mean, standard deviation (SD), and correlation coefficient. Normality of data was examined using the Shapiro-Wilk test and visual distribution assessment (histogram and quantile-quantile (QQ) plot). Qualitative variables were presented in the form of numbers and percentage distribution. Evaluation of the relationship between TF, TFPI and the quantitative variable was examined using the Mann-Whitney test. Quantitative variables were presented as means and SDs. The relationship between TF, TFPI and quantitative variables was examined using the Spearman correlation coefficient.

The analysis was performed using the R package for Windows (version 3.4.2) [20].

\section{Results}

The study included 47 patients (26 females, 21 males, mean age: 46.4) as well as 18 respondents in the control group (12 females, 6 males, mean age: 48.5). The mean concentration of TF in patients with psoriasis was 472.84 $\pm 352.66 \mathrm{pg} / \mathrm{ml}$, and mean concentration of TFPI amounted to $85.87 \pm 85.91 \mathrm{ng} / \mathrm{ml}$. In the control group, the mean TF concentration was $943.42 \pm 562.97 \mathrm{pg} / \mathrm{ml}$, while mean TFPI concentration amounted to $191.38 \pm 130.75 \mathrm{ng} / \mathrm{ml}$. 
A significantly lower TF and TFPI concentration was found in the study group compared to the control group (Table 3, Figures 1, 2).

The mean total cholesterol level in the study group was $200.1 \pm 44.6 \mathrm{mg} / \mathrm{dl}$, whereas in the control group it was $212.4 \pm 43.0 \mathrm{mg} / \mathrm{dl}$. The mean triglyceride concentration in patients with psoriasis was $155.0 \pm 76.1 \mathrm{mg} / \mathrm{dl}$; in the control group it amounted to $119.2 \pm 46.6 \mathrm{mg} / \mathrm{dl}$. No statistically significant differences were observed between total cholesterol and triglyceride levels in either group (Table 4).

However, a significantly lower concentration of LDL and HDL was observed in the study group compared to the control group. Mean LDL cholesterol concentration in the study group was $110.2 \pm 35.2 \mathrm{mg} / \mathrm{dl}$, while in the control group it was $131.5 \pm 35.7 \mathrm{mg} / \mathrm{dl}$. Mean HDL cholesterol concentration in the study group was $51.7 \pm 13.8 \mathrm{mg} / \mathrm{dl}$, and in the control group $57.1 \pm 9.7 \mathrm{mg} / \mathrm{dl}$ (Table 4).

However, no differences were observed in TF and TFPI concentrations in the study group depending on the sex, age, psoriasis severity according to the PASI, duration of psoriasis, positive family history of psoriasis, psoriasis therapy methods, BMI, smoking cigarettes, coexistence of psoriatic arthritis, as well as cardiovascular diseases, diabetes or cancer.

\section{Discussion}

The results of the study showed statistically significant differences in the concentrations of TF and TFPI between patients suffering from psoriasis and those in the control group. These concentrations were lower in the group of patients with psoriasis. It was primarily the level of TF, statistically significantly lower in patients with psoriasis than in the control group, which proved surprising for the authors. Given that psoriasis is currently considered as one of the risk factors for cardiovascular diseases, the low level of plasma TF in these patients may seem puzzling. In many studies conducted to date, it has been observed that high plasma TF concentrations may be the risk factor for thrombosis [21]. TF occurs in the

Table 3. Concentrations of TF and TFPI in the study and control groups

\begin{tabular}{lcc}
\hline Assay & Study group & Control group \\
\hline TF $[\mathrm{pg} / \mathrm{ml}]:$ & & \\
\hline Mean \pm SD & $472.84 \pm 352.66$ & $943.42 \pm 562.97$ \\
\hline Minimum & 251.17 & 196.62 \\
\hline Maximum & 1754.54 & 1658.77 \\
\hline TFPI $[\mathrm{ng} / \mathrm{ml}]:$ & & $191.38 \pm 130.75$ \\
\hline Mean \pm SD & $85.87 \pm 85.91$ & 42.41 \\
\hline Minimum & 35.17 & 392.24 \\
\hline Maximum & 359.10 & \\
\hline
\end{tabular}

SD - standard deviation.

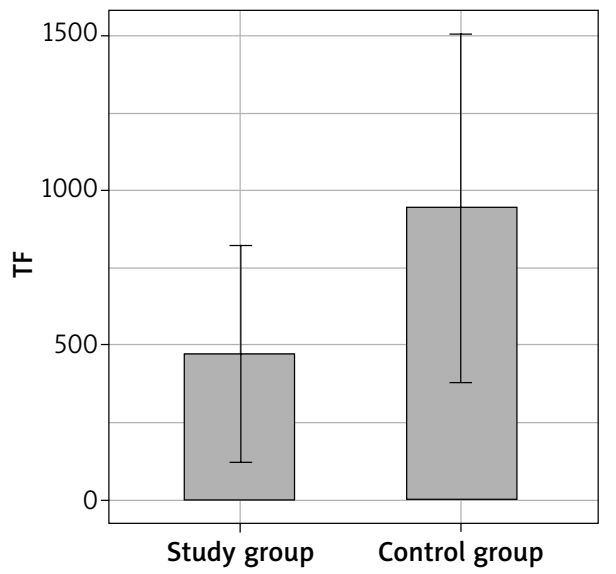

Figure 1. Concentrations of TF in the study and control groups

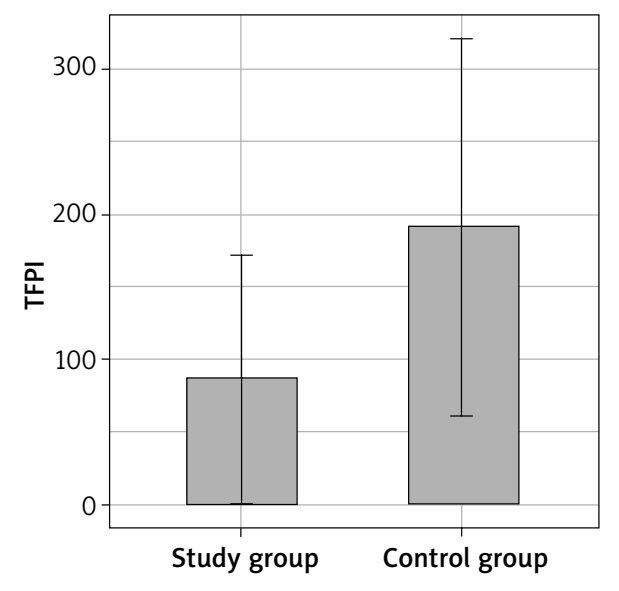

Figure 2. Concentrations of TFPI in the study and control groups 
Table 4. Concentration of lipids in the study and control groups

\begin{tabular}{|c|c|c|c|}
\hline Assay & Study group & Control group & $P$-value \\
\hline Total cholesterol [mg/dl]: & & & 0.17 \\
\hline Mean \pm SD & $200.1 \pm 44.6$ & $212.4 \pm 43.0$ & \\
\hline Minimum & 117 & 115 & \\
\hline Maximum & 224 & 284 & \\
\hline Triglycerides [mg/dl]: & & & 0.09 \\
\hline Mean \pm SD & $155.0 \pm 76.1$ & $119.2 \pm 46.6$ & \\
\hline Minimum & 47 & 61 & \\
\hline Maximum & 351 & 238 & \\
\hline LDL [mg/dl]: & & & 0.03 \\
\hline Mean \pm SD & $110.2 \pm 35.2$ & $131.5 \pm 35.7$ & \\
\hline Minimum & 43 & 62 & \\
\hline Maximum & 201 & 184 & \\
\hline $\mathrm{HDL}[\mathrm{mg} / \mathrm{dl}]:$ & & & 0.02 \\
\hline Mean \pm SD & $51.7 \pm 13.8$ & $57.1 \pm 9.7$ & \\
\hline Minimum & 33 & 37 & \\
\hline Maximum & 98 & 70 & \\
\hline
\end{tabular}

endothelial and vascular smooth muscle cells, in blood monocytes/macrophages, and in tumour cells. Its synthesis and release is stimulated by cell damage as well as cytokines and inflammatory mediators. It can stimulate the proliferation and migration of endothelial and smooth muscle cells, and it is involved in inflammation and neovascularization of tumours [21]. In recent studies, it has been observed that the level of TF is elevated in patients with atherosclerosis [22-24]. However, a study by Migdalski et al. [25] found that plasma TF concentration in patients with advanced carotid atherosclerosis is within normal limits, but the mean TF concentration in the homogenates of atherosclerotic plaque was almost 60 -fold higher than the concentration in plasma. Annex et al. [26] found, however, that the levels of TF in the atherosclerotic plaques in patients with unstable coronary disease are higher than in patients with stable ischaemic heart disease. Perhaps the expression of TF (which occurs on the macrophage-derived foam cells) is higher only in some areas of the symptomatic atherosclerotic plaque, where the concentration of inflammatory cells is higher. A similar situation may also occur in psoriasis, where differences in TF concentrations between healthy skin and blood plasma and psoriatic lesions in the skin can be expected. On the other hand, the existence of microvascular disorders within the psoriatic skin lesions (extension of the capillary loops, defects in the capillary walls, damage to the endothelial cells by proinflamma- tory cytokines such as TNF- $\alpha$ ) may lead to direct contact between TF and the circulating blood [15], which in theory should result in elevated TF levels in the plasma of these patients. Therefore, this issue certainly requires a more thorough examination in the future.

On the contrary, reduced plasma TFPI levels in patients with psoriasis may indicate an increased risk of thrombotic complications in this group of patients. Many studies have shown that a decreased concentration of TFPI is a risk factor for thrombosis in various diseases [21]. TFPI occurs in endothelial cells, monocytes, fibroblasts and megakaryocytes etc. It works by inhibiting factor $X$ and TF/VIla complex, preventing the generation of thrombin, and thrombosis. TFPI also inhibits the proliferation of endothelial cells as well as prevents thrombosis and vascular reocclusion in the course of inflammatory diseases, sepsis and in the rejection of transplants [21, 27, 28]. In addition, the TFPI inhibits synthesis of tumour necrosis factor $\alpha$ (TNF- $\alpha$ ) by monocytes [29]. Increased concentrations of the pro-inflammatory cytokines, for example the TNF- $\alpha$, do play a key role in the development of inflammation in both psoriasis and atherosclerosis. Radziwon et al. [18] revealed that the established risk factors for atherosclerosis (hyperlipidaemia, smoking) directly, albeit to a small extent, affect the TFPI concentration, similarly to vasomotor drugs or medications which improve the rheological properties of red blood cells used in the conservative treatment of occlusive arterial diseases. In 
the present study, there was also no correlation observed between the TFPI value and the cardiovascular disease risk factors coexisting in patients with psoriasis. However, a study by Hansen et al. [30] showed that plasma TFPI correlated with the concentration of LDL cholesterol in people with familial cholesterolaemia. In our study, no correlations were found between the TFPI level and total cholesterol, LDL, HDL and triglycerides levels in any of the examined groups; however, in the group of patients with psoriasis, decreased concentrations of both TFPI as well as LDL and HDL cholesterol fractions were observed. The reduced concentration of TFPI, as a marker of the increased risk of thrombosis, in the future may perhaps be corrected with the use of recombinant TFPI (rTFPI). The use of rTFPI in an experimental animal model prevented thrombosis (and recurrence of thrombosis following thrombolysis), decreased mortality in E. coli-induced sepsis, and also prevented the development of disseminated intravascular coagulation (DIC) syndrome [31].

In our study no correlations were established between the TF and TFPI level and variables such as age, sex, BMI, serum lipid and glucose values (in both groups), or between the TF and TFPI level and psoriasis severity according to the PASI, duration of psoriasis, positive family history of psoriasis, present methods of therapy of psoriasis, coexistence of psoriatic arthritis, cardiovascular diseases, diabetes or tumours in the study group. However, correlations between TF and TFPI values and BMI were established in studies by different authors. When examining diabetic patients, Vambergue et al. observed significant correlations between the TFPI level and $\mathrm{BMI}$ and age. However, there was no significant relationship between the TFPI level and the type of coexisting diabetes (type 1 or 2) [32]. On the other hand, Kopp et al. showed that a reduction in body weight in obese patients is associated with a decrease in the TF level, which may reduce the cardiovascular risk in these patients [33].

\section{Conclusions}

Results obtained here do confirm the observations made by other authors, that there are some important abnormalities in the haemostasis in psoriasis. It seems, however, that a precise explanation of the role of impairments of the external coagulation pathway in psoriasis requires testing on a larger number of patients, as well as additional studies on the TF and TFPI levels in affected skin of patients with psoriasis. However, it is worth emphasizing and is supported by the literature that a low plasma TFPI concentration is a risk factor for deep vein thrombosis and ischaemic heart disease [34-37]. Therefore, it cannot be ruled out that a decrease in the plasma TFPI concentration in patients with psoriasis influences the occurrence of cardiovascular comorbidities. It is therefore necessary to carry out further studies, taking into account the specific clinical data of patients. Further- more, the most recent studies have shown the impact of genetic variants of the TFPI inhibitor on its concentration in blood [37]. Therefore, there is a need for genetic testing of people with psoriasis to identify potential polymorphisms in the gene that encodes TFPI inhibitor.

\section{Acknowledgments}

This publication was supported by the European Regional Development Fund, within the Innovative Economy Operational Program 2007-2013, project "Wrovasc - Integrated Cardiovascular Centre", realized in the Regional Specialist Hospital, Research and Development Centre in Wroclaw (WW) and by Wroclaw Centre of Biotechnology, programme The Leading National Research Centre (KNOW) for years 2014-2018.

\section{Conflict of interest}

The authors declare no conflict of interest.

\section{References}

1. Christophers E. Psoriasis epidemiology and clinical spectrum. Clin Exp Dermatol 2001; 26: 314-20.

2. Nall ML, Faber EM. World epidemiology of psoriasis. In: Psoriasis. Faber EM, Cox AJ (eds.). York Medical Books, New York 1998; 107-58.

3. Kourosh AS, Miner A, Menter A. Psoriasis as the marker of underlying systemic disease. Skin Therapy Lett 2008; 13: 1-5.

4. Reich A, Szepietowski J. Genetic and immunological aspects of the pathogenesis of psoriasis. Wiad Lek 2007; 60: 270-6.

5. Neimann AL, Shin DB, Wang X, et al. Prevalence of cardiovascular risk factors in patients with psoriasis. J Am Acad Dermatol 2006; 55: 829-35.

6. Komorowska O, Bohdan M, Szczerkowska-Dobosz A, et al. Assesment of cardiovascular risk factors in patients with psoriasis. Acta Dermatovenerol Croat 2016; 24: 261-7.

7. Marongiu F, Sorano GG, Bibbo C, et al. Abnormalities in blood coagulation and fibrynolysis in psoriasis. Dermatology 1994; 189: 32-7.

8. Berrettini M, Parise P, Constantini VI, et al. Platelet activation in psoriasis. Thromb Haemost 1985; 53: 195-7.

9. Vanizor KB, Orem A, Cimsit G, et al. Plasma homocysteine and its relationships with atherothrombotic markers in psoriasis patients. Clin Chim Acta 2003; 332: 23-30.

10. Vila L, Cullare C, Sola J, et al. Cyclooxygenase activity is increased in platelets from psoriatic patient. I Invest Dermatol 1991; 97: 922-6.

11. Tamagawa-Mineoka R, Katoh N, Kishimoto S. Platelet activation in patients with psoriasis: increased plasma levels of patelet-derived microparticles and soluble p-sselectin, J Am Acad Dermatol 2010; 62: 621-6.

12. Płatek-Twardoch C. Rozsiane wewnątrznaczyniowe krzepnięcie w chorobach skóry. Przegl Dermatol 1984; 71: 609.

13. Iwan-Ziętek I, Gwieździński Z, Ziętek Z, Kotschy M. Kompleksy plazmina-alfa2-antyplazmina w osoczu krwi chorych na łuszczycę zwykłą. Przegl Dermatol 1999; 86: 2.

14. Radziwon P, Kłoczko J, Kiss B. Współczesna teoria aktywacji i kontroli krzepnięcia krwi. Przew Lek 2004; 11: 50-6. 
15. Asada Y, Marutsuka K, Hatakeyama K, et al. The role of tissue factor In the pathogenesis of thrombosis and atherosclerosis. J Atheroscler Thromb 1998; 4: 135-9.

16. Jabłoński S, Chorzelski T. Choroby skóry. PZWL, Warsaw 1997

17. Kato H. Tissue factor pathway inhibitor: its structure, function and clinical significance. Pol J Pharmacol 1996; 48: 67-72.

18. Radziwon P, Bielawiec M, Kłodzko J, et al. Tissue factor pathway inhibitor (TFPI) in patients with occlusive arterial diseases in consideration with risk factors and conservative treatment of the disease. Acta Angiol 2001; 7: 43-54.

19. Dahm A, van Hylckama Vlieg A, Bendz B, et al. Low levels of tissue factor pathway inhibitor (TFPI) increase the risk of venous thrombosis. Blood 2003; 1001: 4387-92.

20. R Core Team (2017). R: A language and environment for statistical computing. R Foundation for Statistical Computing Vienna, Austria. URL https://www.R-project.org/

21. Kotschy M, Kotschy D, Witkiewicz W. Rola czynnika tkankowego i jego inhibitora w procesie krzepnięcia krwi oraz w powikłaniach zakrzepowych. Kardiol Pol 2010; 68: 1158-62.

22. Misumi K, Ogawa H, Yasue H, et al. Comparison of plasma tissue factor levels in unstable and stable angina pectoris. Am J Cardiol 1998; 81: 22-6.

23. Soejima H, Ogawa $H$, Yasue $H$, et al. Heightened tissue factor associated with tissue factor pathway inhibitor and prognosis in patients with unstable angina. Circulation 1999; 99: 2908-13.

24. Bonderman D, Teml A, Jakowitsch J, et al. Coronary no-reflow is caused by shedding of active tissue factor from dissected atherosclerotic plaque. Blood 2002; 99: 2794-800.

25. Migdalski A, Kotschy M, Jawien A. Tissue factor, tissue factor pathway inhibitor and vascular endothelial growth factora in carotid atherosclerotic plaques. Eur J Vasc Endovasc Surg 2005; 30: 41-7.

26. Annex BH, Denning SM, Channon KM, et al. Differential expression of tissue factor protein in directional atherectomy specimens from patients with stable and unstable coronary syndromes. Circulation 1995; 91: 619-22.

27. Caplice NM, Mueske CS, Kleppe LS, et al. Presence of tissue factor inhibitor in human atherosclerotic plaques is associated with reduced tissue factor activity. Circulation 1998; 98: 1051-3.

28. Gosk-Bierska I, Wysokiński W, Karnicki K, et al. Tissue factor, tissue factor pathway inhibitor and risk factors of atherosclerosis in patients with chronic limbs ischemia: preliminary study. Int Angiol 2008; 27: 296-301.

29. Sabharwal AK, Bajaj SP, Ameri A, et al. Tissue factor pathway inhibitor and von Willebrand factor antigen levels in adult respiratory distress syndrome and in a primate model of sepsis. Am J Respir Crit Care Med 1995; 151: 758-67.

30. Hansen JB, Huseby KR, Sandset PM, et al. Tissue factor pathway inhibitor and lipoproteins: evidence for association with and regulation by LDL in human plasma. Arterioscler Throm 1994; 14: 223-9.

31. Lwaleed BA, Bass PS. Tissue factor pathway inhibitor: structure, biology and involvement in disease. J Pathol 2006; 208: 327-39.

32. Vambergue A, Rugeri L, Gaveriaux V, et al. Factor VII, tissue factor pathway inhibitor, and monocyte tissue factor in diabetes mellitus: influence of type of diabetes, obesity index, and age. Thromb Res 2001; 101: 367-75.

33. Kopp CW, Kopp HP, Steiner S. Weight loss reduces tissue factor in morbidly obese patients. Obes Res 2003; 11: 950-6.
34. Zakai NA, Lutsey PL, Folsom AR, et al. Total tissue factor pathway inhibitor and venous thrombosis. The Longitudinal Investigation of Thromboembolism Etiology. Thromb Haemost 2010; 104: 207-12.

35. Amini-Nekoo A, Futers TS, Moia M, et al. Analysis of the tissue factor pathway inhibitor gene and antigen levels in relation to venous thrombosis. Br J Haematol 2001; 113: 537-43.

36. Johnson KC, Aragaki AK, Jackson R, et al. Tissue factor pathway inhibitor, activated protein $C$ resistance, and risk of coronary heart disease due to combined estrogen plus progestin therapy. Arterioscler Thromb Vasc Biol 2016; 36: 418-24.

37. Naji DH, Tan C, Han F, et al. Significant genetic association of a functional TFPI variant with circulating fibrinogen levels and coronary artery disease. Mol Genet Genomics 2018; 293: $119-28$ 